\title{
Tax competition leading to strict environmental policy
}

\author{
Cees Withagen · Alex Halsema
}

Published online: 12 May 2012

(C) The Author(s) 2012. This article is published with open access at Springerlink.com

\begin{abstract}
We study tax competition when pollution matters. Most notably, we present a dynamic setting, where the supply of capital is endogenous. It is shown that tax competition may involve stricter environmental policy than the cooperative outcome.
\end{abstract}

Keywords Environmental policy $\cdot$ Race to the bottom $\cdot$ Pollution taxation

JEL Classification Q58 · H23

\section{Introduction}

The theoretical and empirical literature on a race to the bottom in terms of environmental standards in case of mobile capital is vast. On the empirical side, Wilson (1997) argues that the fear of a race to the bottom has induced a shift of control of environmental policy from the states to the Federal government (see also Vig and Kraft 1994). List and Gerking (2000), however, do not find any evidence of a race to the bottom in environmental standards when US environmental policy was delegated to the states during the Reagan administration. The survey by Levinson (1997a) is inconclusive. The theoretical paper by Oates and Schwab (1988) is a classic. It shows that a race to the bottom does not occur if governments behave competitively, meaning that in determining the optimal source-based capital tax and the optimal environmental tax, they take the net rate of return on capital in all other jurisdictions as given.

C. Withagen ( $\triangleleft)$

Department of Spatial Economics, VU University Amsterdam, De Boelelaan 1105, 1081 HV

Amsterdam, The Netherlands

e-mail: c.a.a.m.withagen@vu.nl

\section{A. Halsema}

Centre for World Food Studies, VU University Amsterdam, Amsterdam, The Netherlands 
However, if the capital tax is exogenously fixed, the environmental tax will be set too low: A first-best optimum across all jurisdictions commands a higher environmental tax. A recent contribution was made by Ogawa and Wildasin (2009) who extend the Oates and Schwab framework by allowing for transboundary pollution, caused by the use of capital. They show that decentralized decision making results in a first-best optimum if jurisdictions recognize that capital fleeing the country will lead to pollution when employed in another country. These results look surprising, and they can be challenged. It has been put forward that the assumption of a large number of jurisdictions may play a role (Levinson 1997b). List and Mason (2001) find that inclusion of transboundary pollution results in an ambiguous outcome depending on the initial pollution stocks and the level of heterogeneity between two countries. Kim and Wilson (1997) present a second-best model of tax competition and the environment. They include a distortionary labor tax and public goods provision. In equilibrium, the capital tax is equal to zero, and the environmental standard is below the Pigovian level. In their model, revenue from the labor tax is not enough for the public goods provision. By relaxing the environmental standards, more capital can be attracted from abroad, which increases the revenues for financing public goods. Kanbur et al. (1995) also reach this conclusion: Countries will reduce their environmental standards below the Pigovian level in order to attract foreign investors. For an overview, see Rauscher (2000). Kim and Wilson (1997) also suggest, based on an earlier study by Bucovetsky and Wilson (1991), that in a dynamic framework, where savings are endogenous, efficiency might be restored if the capital tax is resident-based. For a more extensive overview regarding a race to the bottom, we refer to Oates (2002).

The present paper offers a general model capable of unifying existing theories as well as a model where governments play a game against each other. In setting the optimal policy, a government no longer takes the net rate of return for granted but determines the different tax rates, given the tax rates imposed by the other government. The main innovative feature we offer is true dynamics. Hence, the supply of capital is no longer exogenous, but it is the result of savings decisions based on expectations of the investing agents regarding future tax regimes. We show that in this context a counterintuitive result may be obtained. Numerical examples are provided showing an emission tax rate that is higher in the Nash equilibrium than under cooperation. The main reason for this phenomenon is that under cooperation the capital tax will be higher than under competition. This induces consumers to save less. Hence, under competition, there will be more capital available which may, ceteris paribus, lead to a higher demand for environmental quality, and hence gives rise to a more strict environmental policy. Moreover, marginal product of the polluting input is higher. Transboundary pollution will have a mitigating effect, since under competition a jurisdiction neglects the effect of pollution generated at home for the welfare in the other jurisdictions. This idea was explored some years ago in a paper by Marsiliani et al. (2004). However, the present model is more general in several respects. In particular we allow for decreasing returns to scale. Moreover, in the policy game that we consider the strategies consist of taxes, including a pollution tax and a corporate tax. There are related papers that analyze savings behavior under tax competition. See Ha 
and Sibert (1997), Lejour and Verbon (1997), and Klein et al. (2005), but they do not include environmental externalities. ${ }^{1}$

\section{The model}

The objective of the present paper is to add dynamics to the conventional framework. In the model, we analyze an economy consisting of two countries, home and foreign, with activities extending over two periods of time. We aim at showing that in the cooperative equilibrium the pollution tax can be lower than in the noncooperative equilibrium. We restrict ourselves to the case of identical countries and we take specific functional forms for the preferences, the damage functions, and the production functions. Consumers are homogeneous and derive utility from consumption in the first and second period, and disutility from second period pollution resulting from investments made in the first period, as well as utility from a public good that is provided in the second period only.

We describe the home economy. The foreign economy's variables are denoted by hats. The welfare function of the representative consumer reads

$$
U\left(c_{1}, c_{2}, g, x, \widehat{x}\right)=\frac{c_{1}^{1-\sigma}}{1-\sigma}+\eta\left[\frac{c_{2}^{1-\sigma}}{1-\sigma}+\varepsilon \frac{g^{1-\sigma}}{1-\sigma}-\omega x-v \widehat{x}\right]
$$

Here, $c_{1}, c_{2}, g, x$, and $\widehat{x}$ denote first period consumption, second period consumption, consumption of the public good, pollution generated in the home country, and pollution generated in the foreign country, respectively. The damage function is linear, with marginal damage from pollution generated at home equal to $\omega$ and marginal damage attributable to transboundary pollution equal to $v$. In the instantaneous utility functions for consumption, the parameter $\sigma$ is the negative of the elasticity of marginal utility. In the welfare function, $\eta$ is the discount factor. The parameter $\varepsilon$ denotes the relative weight attached to public consumption.

At the outset of the first period, the individual holds lump-sum wealth $w$, which may be used for three purposes: period-1 consumption $c_{1}$, domestic investment $\bar{k}_{h}$, and investment abroad $\bar{k}_{f}$. Therefore,

$$
c_{1}=w-\bar{k}_{h}-\bar{k}_{f}
$$

In the second period, the individual may choose to relocate capital across borders, but at a cost. This process results in $k_{h}$ and $k_{f}$, the actual inputs of home owned capital in home production and foreign production, respectively. Hence, total capital used in domestic production is given by

$$
k=k_{h}+\widehat{k}_{f}
$$

\footnotetext{
${ }^{1}$ Also, the literature that focuses on plant location instead of capital movements (see in this respect, among others, Hoel 1997; Krumm and Wellisch 1995; Markusen et al. 1995; Motta and Thisse 1994; Rauscher 1995; Ulph 1994; Venables 1999; Wellisch 1995) abstracts from the issue of endogenous savings.
} 
where $\widehat{k}_{f}$ is foreign investment in home. Similarly,

$$
\widehat{k}=\widehat{k}_{h}+k_{f}
$$

Of course it must hold that

$$
\begin{aligned}
& \bar{k}=k_{h}+k_{f} \\
& \widehat{\bar{k}}=\widehat{k}_{h}+\hat{k}_{f}
\end{aligned}
$$

Production takes place in the second period according to a Cobb-Douglas technology employing capital $k$ and the polluting input $x$.

$$
y=k^{\alpha} x^{\beta}, \quad \text { with } \alpha+\beta \leq 1
$$

The representative firm hires capital at the rental rate $r$, and pays a pollution tax $t$. It then follows from profit maximization that

$$
\begin{aligned}
& r=\alpha k^{\alpha-1} x^{\beta} \\
& t=\beta k^{\alpha} x^{\beta-1}
\end{aligned}
$$

Profits made by the firm are

$$
\pi=(1-\alpha-\beta) k^{\alpha} x^{\beta}
$$

The second period budget constraint of the representative individual reads

$$
c_{2}=\left(1-\tau_{h}\right) r k_{h}+\left(1-\widehat{\tau}_{f}\right) \widehat{r} k_{f}+\delta \pi-\frac{\gamma}{2}\left(k_{h}-\bar{k}_{h}\right)^{2}-\frac{\gamma}{2}\left(k_{f}-\bar{k}_{f}\right)^{2}
$$

Here, $\tau_{h}$ is the capital tax imposed on revenues on home owned capital, and $\widehat{\tau}_{f}$ the foreign tax on home owned capital revenues. The relocation costs are quadratic, with parameter $\gamma>0$. The corporate profit tax is $\delta$, which is given for the time being. After the two governments have set their taxes, the representative individual in the home country maximizes consumption, i.e., maximizes the right-hand side of (8) by optimally moving capital across borders, taking into account that $k_{h}+k_{f}=\bar{k}_{h}+\bar{k}_{f}$. She ignores the potential effect of her decision on profits $\pi$. Given the governments' decisions, this yields the individual's optimal allocation of capital. The agent, confronted with tax differentials, minimizes her cost given her initial allocation, yielding

$$
\begin{aligned}
& k_{h}=\bar{k}_{h}+\frac{1}{2 \gamma}\left(\left(1-\tau_{h}\right) r-\left(1-\widehat{\tau}_{f}\right) \widehat{r}\right) \\
& k_{f}=\bar{k}_{f}+\frac{1}{2 \gamma}\left(\left(1-\widehat{\tau}_{f}\right) \widehat{r}-\left(1-\tau_{h}\right) r\right)
\end{aligned}
$$

Here, $\hat{\tau}_{f}$ is the foreign tax on home owned capital revenues. Similarly, for the foreign representative capital owner

$$
\widehat{k}_{h}=\widehat{\bar{k}}_{h}+\frac{1}{2 \gamma}\left(\left(1-\widehat{\tau}_{h}\right) \widehat{r}-\left(1-\tau_{f}\right) r\right)
$$




$$
\widehat{k}_{f}=\widehat{\bar{k}}_{f}+\frac{1}{2 \gamma}\left(\left(1-\tau_{f}\right) r-\left(1-\widehat{\tau}_{h}\right) \widehat{r}\right)
$$

Here, $\tau_{f}$ is the home tax on foreign owned capital revenues. Then as a final step in this procedure we will consider relocation at infinitely small cost, i.e., for $\gamma \rightarrow 0$. The governments know this reallocation behavior, which is henceforth internalized by them when taking their actions. The government's budget constraint reads

$$
g=(1-\delta) \pi+\tau_{h} r k_{h}+\tau_{f} r \widehat{k}_{f}+t x
$$

\section{Equilibrium}

We consider both a noncooperative as well as a cooperative equilibria.

In the noncooperative equilibrium four stages can be distinguished.

1. At the outset of period 1, the representative individual decides on savings and investment allocations. The home consumer determines $\left(\bar{k}_{h}, \bar{k}_{f}\right)$ whereas the foreign consumer sets $\left(\widehat{\bar{k}}_{h}, \widehat{\bar{k}}_{f}\right)$. These decisions are made based on rational predictions of future governments' policies.

2. At the outset of period 2, the home government chooses $\tau_{h}, \tau_{f}$, and $t$ (taking as given $\widehat{\tau}_{h}, \widehat{\tau}_{f}$, and $\widehat{t}$ ) so as to maximize the welfare of the resident representative individual. Similarly, the foreign government chooses $\widehat{\tau}_{h}, \widehat{\tau}_{f}$, and $\widehat{t}$ (taking $\tau_{h}, \tau_{f}$, and $t$ as given). For the time being, we assume an a priori fixed corporate tax.

3. Individuals observing the governments' decisions may then choose to relocate capital.

4. Taxation, public spending, production, and hence pollution as well as consumption take place.

The cooperative equilibrium differs from the noncooperative equilibrium only in that at the outset of period 2 both governments choose $\tau_{h}, \tau_{f}, t, \widehat{\tau}_{h}, \widehat{\tau}_{f}$, and $\widehat{t}$ so as to maximize the sum of utilities of both representative individuals.

The timing of the policy game captures the feature that the initial allocation of capital is fixed when the government sets the capital tax, and that individuals' savings depend on the anticipated capital tax. Hence, individuals make their savings decision at the outset of period 1 , and the government makes the tax decision at the beginning of period 2 .

\subsection{Second-period equilibrium}

The cooperative second-period equilibrium is easy to calculate. Given that the countries are identical, the capital taxes are all the same as well as the capital stocks at the outset of the second period. Moreover, there is no need for reallocation. Hence, the problem is just to maximize

$$
W=\frac{c^{1-\sigma}}{1-\sigma}+\varepsilon \frac{g^{1-\sigma}}{1-\sigma}-\omega x-\nu x
$$


subject to

$$
\begin{aligned}
& c=((1-\tau) \alpha+\delta(1-\alpha-\beta)) \bar{k}^{\alpha} x^{\beta} \\
& g=(1-(1-\tau) \alpha-\delta(1-\alpha-\beta)) \bar{k}^{\alpha} x^{\beta}
\end{aligned}
$$

where we have omitted the index for the period of time. It readily follows that the Samuelson condition holds

$$
1=\frac{c^{-\sigma}}{\varepsilon g^{-\sigma}}
$$

from which the tax rate $\tau$ can uniquely be determined. Moreover, the pollution tax is Pigovian and, therefore, equals marginal damage, normalized by the marginal utility of consumption

$$
\frac{v+\omega}{[\alpha(1-\tau)+\delta(1-\alpha-\beta)]^{-\sigma}\left(\bar{k}^{\alpha} x^{\beta}\right)^{-\sigma}}=\frac{v+\omega}{c^{-\sigma}}=\beta \bar{k}^{\alpha} x^{\beta-1}=t
$$

So, for every initial second period capital stock, we can determine the optimal pollution tax as well as the rate of pollution. Note that the capital tax is independent of the initial capital stock. Moreover, foreign investments are not needed at all. It is also straightforward to see that if the corporate tax is a policy instrument as well, we have an additional degree of freedom. Any combination of capital taxes and corporate taxes satisfying (14) is optimal.

It is considerably more complicated to determine the second-period non-cooperative equilibrium. The technical details are given in the Appendix. Here, we restrict ourselves to giving the results and providing the economic intuition. The home government chooses $\tau_{h}, \tau_{f}$ and $t$ (taking $\widehat{\tau}_{h}, \widehat{\tau}_{f}$ and $\widehat{t}$ as given) so as to maximize period2 utility of the resident individual

$$
W=\frac{c^{1-\sigma}}{1-\sigma}+\varepsilon \frac{g^{1-\sigma}}{1-\sigma}-\omega x-v \widehat{x}
$$

subject to the constraints: (1)-(2), (5), and (6) and the foreign counterpart (7)-(13). The initial capital endowments $\bar{k}$ and $\widehat{\bar{k}}$ are given to the governments. Given the fact that countries are symmetric, the equilibrium is characterized by equal tax rates and allocations across the two countries. Consequently, no reallocation of capital from one country to another will take place. This can in a convenient way be captured by assuming that the reallocation cost parameter $\gamma$ converges to zero. The most remarkable feature of the solution is that given $\bar{k}$ and $\widehat{\bar{k}}$ there are unique positive optimal allocations of capital to home and foreign: $k_{h}, k_{f}, \widehat{k}_{h}$, and $\widehat{k}_{f}$. To see why this is the case, let us first assume that the corporate tax is a policy instrument and is not subject to any restrictions. In that case, the Samuelson condition will hold since the marginal utilities of private and public consumption are equal (as a consequence of maximization of the Lagrangian of the problem with respect to the corporate tax (see the Appendix)). Then the countries enter into a race to the bottom when it comes to capital taxation in order to attract capital. One reason is to benefit from the profits of higher production. Another reason is that, given the other country's pollution 
tax, higher capital input in the other country will also increase its emissions, which are harmful. For the model at hand, it can be shown that the optimal noncooperative capital tax satisfies

$$
\frac{\beta v+(1-\beta) \omega}{(1-\beta) \omega}=(1-\tau)
$$

Hence, the tax is negative. It is the more negative the larger the marginal damage of pollution flowing in from the other country relative to the marginal damage of the country's own emissions. Moreover, the higher the production elasticity of emissions the more negative the capital tax is. It is also straightforward that in the equilibrium the pollution tax is Pigovian, but only taking local pollution into account.

$$
\frac{\omega}{c^{-\sigma}}=t
$$

Next, we turn to the case of an a priori given corporate tax rate, thereby allowing for a deviation from the Samuelson rule. In an equilibrium, we still have identical capital tax rates across countries, and countries will not discriminate between home owned and foreign owned capital. Define

$$
z(\tau) \equiv \frac{1}{\varepsilon}\left(\frac{(1-\tau) \alpha+\delta(1-\alpha-\beta)}{1-\alpha(1-\tau)-\delta(1-\alpha-\beta)}\right)^{-\sigma}
$$

Then the second-period noncooperative equilibrium (in the limit, for $\gamma \rightarrow 0$ ) can be characterized as follows:

$$
\begin{aligned}
& \frac{\beta \nu+(1-\beta) \omega}{\omega}=(1-\tau) \frac{(1-z(\tau))(1-\alpha-\beta)+(1-\beta)}{1-\delta(1-z(\tau))(1-\alpha-\beta)} \\
& t=\frac{\omega}{(1-\delta(1-\alpha-\beta)) \varepsilon g^{-\sigma}+\delta(1-\alpha-\beta) c^{-\sigma}} \\
& z(\tau)=\frac{c_{2}^{-\sigma}}{\varepsilon g^{-\sigma}} \\
& z(\tau)=1-\frac{k_{f}}{k_{h}}
\end{aligned}
$$

The proof is given in the Appendix. Several remarks are in order. First of all, if the corporate tax is close to the optimal one, we are back in the previous case of the endogenous corporate tax. Consequently, if the given corporate tax happens to be close to the optimal one, we can still have a negative capital tax. We also see that for a given initial capital endowment there is a unique equilibrium allocation between foreign and home. This is a consequence of the trade off between the benefits of production at home, with the higher profits and production abroad, yielding less pollution at home. We also see that the equilibrium pollution tax has the flavor of a Pigovian tax, but now the local marginal damage is normalized by a weighted sum of the marginal utilities of private and public consumption.

Comparing the cooperative and the noncooperative equilibrium, we note that competition takes place by means of the capital tax. Indeed, regardless of the initial conditions, the noncooperative capital tax is smaller than the cooperative capital tax 
$\tau^{\text {coop }}>\tau^{\text {noncoop }}$. This holds regardless of the initial conditions. A comparison of the pollution taxes is less straightforward because the capital stocks differ between different regimes. This is the subject of the next section.

\subsection{Endogenous savings}

For each regime (cooperation or noncooperation) the individual agents anticipate the capital tax as well as the equilibrium interest rate in the second period. The individual chooses the amount of investment in order to maximize the utility from consumption

$$
U\left(c_{1}, c_{2}\right)=\frac{c_{1}^{1-\sigma}}{1-\sigma}+\eta \frac{c_{2}^{1-\sigma}}{1-\sigma}
$$

Written in terms of investment this is

$$
U\left(c_{1}, c_{2}\right)=\frac{(w-k)^{1-\sigma}}{1-\sigma}+\eta \frac{[(1-\tau) r k+\delta \pi]^{1-\sigma}}{1-\sigma}
$$

Indeed, the agent knows that the net returns on capital do not differ across countries. Moreover, the agent rightly assumes there is no need for relocation of capital. As is standard we assume that each individual is "small" and cannot affect the profits of the firm when making her savings decision. This implies that the pollution taxes do not play a direct role in the agent's decision problem. Maximization with respect to $k$ yields

$$
k=\frac{\eta^{\frac{1}{\sigma}}[(1-\tau) r]^{\frac{1-\sigma}{\sigma}}}{1+\eta^{\frac{1}{\sigma}}[(1-\tau) r]^{\frac{1-\sigma}{\sigma}}} w-\frac{\delta \pi}{(1-\tau) r+\eta^{\frac{1}{\sigma}}[(1-\tau) r]^{\frac{1}{\sigma}}}
$$

Another way of writing this is

$$
\frac{k}{(w-k)^{\sigma}}=\eta(1-\tau) \alpha[\alpha(1-\tau)+\delta(1-\alpha-\beta)]^{-\sigma}\left(k^{\alpha} x^{\beta}\right)^{1-\sigma}
$$

\section{Strict environmental policy in the non-cooperative equilibrium}

Given the second-period tax rates (giving $x$ as a function of $k$ ) we can now determine the full cooperative and noncooperative equilibrium. The main question we wish to address is whether in a cooperative equilibrium environmental policy is more stringent or more lenient than in the noncooperative equilibrium. We have seen before that the capital tax is higher in the cooperative equilibrium. This will trigger less investments in the cooperative equilibrium. Then it may be the case that the emission tax is low because emissions are low by themselves, whereas in the noncooperative regime the producers, having more capital at their disposal, should be more discouraged to emit. Obviously, it is insurmountable to provide a full analytical answer. For that reason, we rely on some numerical exercises.

We take $\beta=0.2, \gamma=0, \varepsilon=2.186, \eta=0.9, \sigma=0.319202, \omega=0.3, w=3$. Furthermore, we take the production elasticity of capital $\alpha$, profits after taxation $\delta$, and 


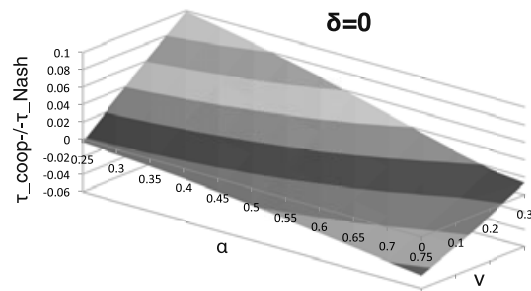

$\delta=0.1$
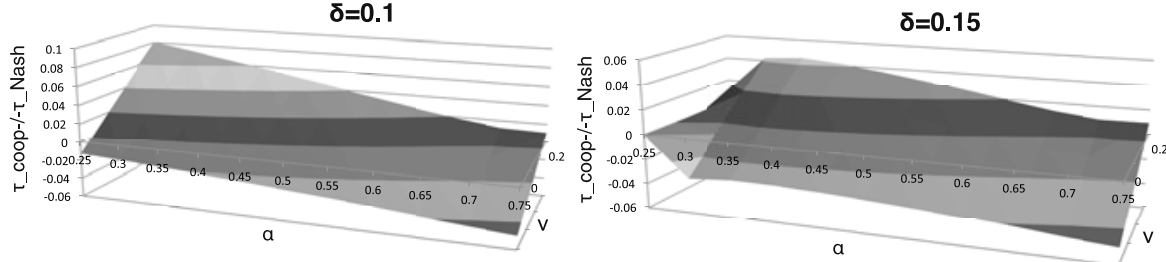

Fig. 1 The difference between environmental taxation under a regime of cooperation and under a regime Nash bargaining for different levels of $\delta, \alpha$, and $v$

Table 1 Levels of production input and corresponding tax rates in a competitive and in a cooperative setting for two different levels of production elasticity of capital

\begin{tabular}{|c|c|c|c|c|}
\hline & \multicolumn{2}{|l|}{$\alpha=0.4$} & \multicolumn{2}{|c|}{$\alpha=0.45$} \\
\hline & Nash & Cooperative & Nash & Cooperative \\
\hline$\tau$ & 0.1444 & 0.8000 & 0.1360 & 0.8222 \\
\hline$k$ & 0.5079 & 0.1206 & 0.5554 & 0.1063 \\
\hline$x$ & 0.1454 & 0.6829 & 1.5020 & 0.6007 \\
\hline$t$ & 0.1131 & 0.1164 & 0.1109 & 0.1096 \\
\hline
\end{tabular}

the transboundary pollution $v$ as pivotal parameters. Figure 1 gives the difference between environmental taxation under the cooperative and the non-cooperative equilibrium (hence, a positive number implies that environmental taxation is higher in the cooperative equilibrium).

As can readily be observed from the figure, environmental taxes may be lower under cooperation compared to noncooperation. Which regime leads to higher taxation depends among others on the production technology used. A higher production elasticity of capital, as well as a reduction in pollution from abroad and a reduction in profit taxation result in a situation in which it is more likely that there is lower taxation under the cooperative equilibrium compared to the noncooperative equilibrium.

Table 1 provides the results of some numerical exercises for the case where $\alpha$ equals either 0.4 or 0.45 while $\delta$ is fixed at 0 and $v=0.1$.

As can be observed from the table, pollution taxes are not necessarily higher under one regime compared to the other. Whether we have a race to the bottom will thus depend on the parameter values used. Furthermore, the results confirm that in a competitive setting more capital is available. Due to a higher availability of capital, the polluting good becomes more productive, leading to a higher demand for the polluting good, which might induce higher environmental taxes. However, if pollu- 
tion is transboundary, this effect is mitigated. Which effect dominates depends on the setting.

Besides the government taxing companies, returns on capital and pollution the government could also opt for subsidizing companies by applying a negative $\delta$. For example, the case where $\delta=-0.1, \alpha=0.5$, and $v=0.1$ would result in a strong increase in environmental taxation under the cooperative equilibrium while there are limited effects on the noncooperative equilibrium. Other implications are a reduction in taxes on returns on capital as well as an increase in government spending. This is the result of an increase in capital in the home country in the second period. Given the implications of a change in $\delta$, this warrants a search for the optimal $\delta$. Unfortunately, this search is only possible for the cooperative equilibrium with the usage of the fact that $\frac{\lambda_{c}}{\lambda_{g}}$ has to equal 1 . The optimal $\delta$ turns out to equal -1.67 when $\alpha=0.5$ and $v=0.1$. This also yields a negative taxation on returns on capital.

\section{Conclusion}

The paper provides a dynamic model of tax competition in a world with transboundary pollution. Most notably, due to introducing dynamics, the supply of capital is no longer fixed nor is the return on capital. Agents determine their savings and thereby available capital in the next period based on future expected tax regimes. Without dynamics and with a fixed return on capital and with optimal nondistortionary taxes the resulting equilibrium equals the autarky situation. With distortionary taxes, emission taxes are higher in cooperation compared to the Nash equilibrium. Introduction of dynamics will yield the same results if nondistortionary taxes are available. If these taxes are not available results are no longer unambiguous. Whether the competitive case or the cooperative case has the more stringent policy depends on the parameter values. The ambiguity originates from opposing factors. In a competitive case, there is a higher demand for the polluting good due to a higher availability of capital while the transboundary characteristic of the pollution reduces the need for a higher pollution tax. Thus, with one production technology, we might experience a race to the bottom while with another technology this might not be the case.

Acknowledgements The authors wish to thank Harry Verbon, Cornelia van Wesenbeeck, and the referees for their useful comments.

Open Access This article is distributed under the terms of the Creative Commons Attribution License which permits any use, distribution, and reproduction in any medium, provided the original author(s) and the source are credited.

\section{Appendix: Second period noncooperative equilibrium}

We omit the time index "2", for the sake of notation only. The home government solves the following optimization problem:

$$
\max \frac{c^{1-\sigma}}{1-\sigma}+\epsilon \frac{g^{1-\sigma}}{1-\sigma}-[\omega x+v \widehat{x}]
$$


subject to

$$
\begin{aligned}
& c=\left(1-\tau_{h}\right) r k_{h}+\left(1-\widehat{\tau}_{f}\right) \widehat{r}_{f}+\delta\left(k^{\alpha} x^{\beta}-r k-t x\right) \\
& \quad-\frac{1}{2} \gamma\left(k_{h}-\bar{k}_{h}\right)^{2}-\frac{1}{2} \gamma\left(k_{f}-\bar{k}_{f}\right)^{2} \\
& g= \tau_{h} r k_{h}+\tau_{f} r \widehat{k}_{f}+t x+(1-\delta)\left(k^{\alpha} x^{\beta}-r k-t x\right) \\
& k_{h}-\bar{k}_{h}=\frac{1}{2 \gamma}\left(\left(1-\tau_{h}\right) r-\left(1-\widehat{\tau}_{f}\right) \widehat{r}\right) \\
& k_{f}-\bar{k}_{f}=\frac{1}{2 \gamma}\left(\left(1-\widehat{\tau}_{f}\right) \widehat{r}-\left(1-\tau_{h}\right) r\right) \\
& \widehat{k}_{h}-\widehat{\bar{k}}_{h}=\frac{1}{2 \gamma}\left(\left(1-\widehat{\tau}_{h}\right) \widehat{r}-\left(1-\tau_{f}\right) r\right) \\
& \widehat{k} f-\widehat{\bar{k}}_{f}=\frac{1}{2 \gamma}\left(\left(1-\tau_{f}\right) r-\left(1-\widehat{\tau}_{h}\right) \widehat{r}\right) \\
& r=\alpha k^{\alpha-1} x^{\beta} \\
& \widehat{r}=\alpha \widehat{k}^{\alpha-1} \widehat{x}^{\beta} \\
& t=\beta k^{\alpha} x^{\beta-1} \\
& \widehat{t}=\beta \widehat{k}^{\alpha} \widehat{x}^{\beta-1} \\
& k=k_{h}+\widehat{k}_{f} \\
& \widehat{k}=\widehat{k}_{h}+k_{f}
\end{aligned}
$$

For the time being, the corporate tax rate $(1-\delta)$ is exogenous. The Lagrangian reads

$$
\begin{aligned}
L= & \frac{c^{1-\sigma}}{1-\sigma}+\varepsilon \frac{g^{1-\sigma}}{1-\sigma}-[\omega x+v \widehat{x}] \\
& +\lambda_{c}\left[\left(1-\tau_{h}\right) r k_{h}+\left(1-\widehat{\tau}_{f}\right) \widehat{r}_{f}+\delta\left(k^{\alpha} x^{\beta}-r k-t x\right)\right. \\
& \left.-\frac{1}{2} \gamma\left(k_{h}-\bar{k}_{h}\right)^{2}-\frac{1}{2} \gamma\left(k_{f}-\bar{k}_{f}\right)^{2}-c\right] \\
& +\lambda_{g}\left[\tau_{h} r k_{h}+\tau_{f} r \widehat{k}_{f}+t x+(1-\delta)\left(k^{\alpha} x^{\beta}-r k-t x\right)-g\right] \\
& +\mu_{h}\left[k_{h}-\bar{k}_{h}-\frac{1}{2 \gamma}\left(\left(1-\tau_{h}\right) r-\left(1-\widehat{\tau}_{f}\right) \widehat{r}\right)\right] \\
& +\mu_{f}\left[k_{f}-\bar{k}_{f}-\frac{1}{2 \gamma}\left(\left(1-\widehat{\tau}_{f}\right) \widehat{r}-\left(1-\tau_{h}\right) r\right)\right] \\
& +\widehat{\mu}_{h}\left[\widehat{k}_{h}-\widehat{\bar{k}}_{h}-\frac{1}{2 \gamma}\left(\left(1-\widehat{\tau}_{h}\right) \widehat{r}-\left(1-\tau_{f}\right) r\right)\right]
\end{aligned}
$$




$$
\begin{aligned}
& +\widehat{\mu}_{f}\left[\widehat{k}_{f}-\widehat{\bar{k}}_{f}-\frac{1}{2 \gamma}\left(\left(1-\tau_{f}\right) r-\left(1-\widehat{\tau}_{h}\right) \widehat{r}\right)\right] \\
& +\kappa\left[\alpha k^{\alpha-1} x^{\beta}-r\right] \\
& +\widehat{\kappa}\left[\alpha \widehat{k}^{\alpha-1} \widehat{x}^{\beta}-\widehat{r}\right] \\
& +\varphi\left[\beta k^{\alpha} x^{\beta-1}-t\right] \\
& +\widehat{\varphi}\left[\beta \widehat{k}^{\alpha} \widehat{x}^{\beta-1}-\widehat{t}\right] \\
& +\psi\left[k-k_{h}-\widehat{k}_{f}\right] \\
& +\widehat{\psi}\left[\widehat{k}-\widehat{k}_{h}-k_{f}\right]
\end{aligned}
$$

The first-order conditions for an interior solution read

$$
\begin{aligned}
& \frac{\partial L}{\partial c}=c^{-\sigma}-\lambda_{c}=0 \\
& \frac{\partial L}{\partial g}=\varepsilon g^{-\sigma}-\lambda_{g}=0 \\
& \frac{\partial L}{\partial x}=-\omega+\lambda_{g} t+\kappa \alpha \beta k^{\alpha-1} x^{\beta-1}+\varphi \beta(\beta-1) k^{\alpha} x^{\beta-2}=0 \\
& \frac{\partial L}{\partial \widehat{x}}=-v+\widehat{\kappa} \alpha \beta \widehat{k}^{\alpha-1} \widehat{x}^{\beta-1}+\widehat{\varphi} \beta(\beta-1) \widehat{k}^{\alpha} \widehat{x}^{\beta-2}=0 \\
& \frac{\partial L}{\partial k_{h}}=\lambda_{c}\left[\left(1-\tau_{h}\right) r-\gamma\left(k_{h}-\bar{k}_{h}\right)\right]+\lambda_{g} \tau_{h} r+\mu_{h}-\psi=0 \\
& \frac{\partial L}{\partial k_{f}}=\lambda_{c}\left[\left(1-\widehat{\tau}_{f}\right) \widehat{r}-\gamma\left(k_{f}-\bar{k}_{f}\right)\right]+\mu_{f}-\widehat{\psi}=0 \\
& \frac{\partial L}{\partial \widehat{k}_{h}}=\widehat{\mu}_{h}-\widehat{\psi}=0 \\
& \frac{\partial L}{\partial \widehat{k}_{f}}=\lambda_{g} \tau_{f} r+\widehat{\mu}_{f}-\psi=0 \\
& \frac{\partial L}{\partial \tau_{h}}=-\lambda_{c} r k_{h}+\lambda_{g} r k_{h}+\frac{\mu_{h}}{2 \gamma} r-\frac{\mu_{f}}{2 \gamma} r=0 \\
& \frac{\partial L}{\partial \tau_{f}}=\lambda_{g} r \widehat{k}_{f}-\frac{\widehat{\mu}_{h}}{2 \gamma} r+\frac{\widehat{\mu}_{f}}{2 \gamma} r=0 \\
& \frac{\partial L}{\partial t}=-\lambda_{c} \delta x+\lambda_{g}(1-\delta)(-x)+\lambda_{g} x-\varphi=0 \\
& \frac{\partial L}{\partial r}=0=\lambda_{c}\left[\left(1-\tau_{h}\right) k_{h}-\delta k\right]+\lambda_{g}\left[\tau_{h} k_{h}+\tau_{f} \widehat{k}_{f}-(1-\delta) k\right] \\
& -\frac{\mu_{h}}{2 \gamma}\left(1-\tau_{h}\right)+\frac{\mu_{f}}{2 \gamma}\left(1-\tau_{h}\right)+\frac{\widehat{\mu}_{h}}{2 \gamma}\left(1-\tau_{f}\right)-\frac{\widehat{\mu}_{f}}{2 \gamma}\left(1-\tau_{f}\right)-\kappa
\end{aligned}
$$




$$
\begin{aligned}
& \frac{\partial L}{\partial \widehat{r}}= \lambda_{c}\left(1-\widehat{\tau}_{f}\right) k_{f}+\frac{\mu_{h}}{2 \gamma}\left(1-\widehat{\tau}_{f}\right)-\frac{\mu_{f}}{2 \gamma}\left(1-\widehat{\tau}_{f}\right) \\
&-\frac{\widehat{\mu}_{h}}{2 \gamma}\left(1-\widehat{\tau}_{h}\right)+\frac{\widehat{\mu}_{f}}{2 \gamma}\left(1-\widehat{\tau}_{h}\right)-\widehat{\kappa}=0 \\
& \frac{\partial L}{\partial k}= \kappa \alpha(\alpha-1) k^{\alpha-2} x^{\beta}+\varphi \alpha \beta k^{\alpha-1} x^{\beta-1}+\psi=0 \\
& \frac{\partial L}{\partial \widehat{k}}=\widehat{\kappa} \alpha(\alpha-1) \widehat{k}^{\alpha-2} \widehat{x}^{\beta}+\widehat{\varphi} \alpha \beta \widehat{k}^{\alpha-1} \widehat{x}^{\beta-1}+\widehat{\psi}=0
\end{aligned}
$$

In a symmetric equilibrium, we have $\tau_{h}=\tau_{f}=\widehat{\tau}_{h}=\widehat{\tau}_{f}=\tau, r=\widehat{r}, x=\widehat{x}, k_{f}=\widehat{k}_{f}$, $k_{h}=\widehat{k}_{h}, k=\widehat{k}, k_{h}=\bar{k}_{h}, k_{f}=\bar{k}_{f}, \widehat{k}_{h}=\widehat{\bar{k}}_{h}, \widehat{k}_{f}=\widehat{\bar{k}}_{f}$. Hence

$$
\begin{aligned}
& c^{-\sigma}=\lambda_{c} \\
& \varepsilon g^{-\sigma}=\lambda_{g} \\
& \omega=\lambda_{g} t+\kappa \alpha \beta k^{\alpha-1} x^{\beta-1}+\varphi \beta(\beta-1) k^{\alpha} x^{\beta-2} \\
& v=\widehat{\kappa} \alpha \beta k^{\alpha-1} x^{\beta-1}+\widehat{\varphi} \beta(\beta-1) k^{\alpha} x^{\beta-2} \\
& \lambda_{c}(1-\tau) r+\lambda_{g} \tau r+\mu_{h}-\psi=0 \\
& \lambda_{c}(1-\tau) r+\mu_{f}-\widehat{\psi}=0 \\
& \widehat{\mu}_{h}=\widehat{\psi} \\
& \widehat{\mu}_{f}=\psi-\lambda_{g} \tau r \\
& k_{h}\left(\lambda_{g}-\lambda_{c}\right)+\frac{\mu_{h}}{2 \gamma}-\frac{\mu_{f}}{2 \gamma}=0 \\
& \lambda_{g} k_{f}-\frac{\widehat{\mu}_{h}}{2 \gamma}+\frac{\widehat{\mu}_{f}}{2 \gamma}=0 \\
& \varphi=\left(\lambda_{g}-\lambda_{c}\right) \delta x \\
& \lambda_{c}\left[(1-\tau) k_{h}-\delta k\right]+\lambda_{g}\left[\tau k_{h}+\tau k_{f}-(1-\delta) k\right] \\
& -\frac{\mu_{h}}{2 \gamma}(1-\tau)+\frac{\mu_{f}}{2 \gamma}(1-\tau)+\frac{\widehat{\mu}_{h}}{2 \gamma}(1-\tau)-\frac{\widehat{\mu}_{f}}{2 \gamma}(1-\tau)=\kappa \\
& \lambda_{c}(1-\tau) k_{f}+\frac{\mu_{h}}{2 \gamma}(1-\tau)-\frac{\mu_{f}}{2 \gamma}(1-\tau)-\frac{\widehat{\mu}_{h}}{2 \gamma}(1-\tau)+\frac{\widehat{\mu}_{f}}{2 \gamma}(1-\tau)=\widehat{\kappa} \\
& \kappa \alpha(\alpha-1) k^{\alpha-2} x^{\beta}+\varphi \alpha \beta k^{\alpha-1} x^{\beta-1}+\psi=0 \\
& \widehat{\kappa} \alpha(\alpha-1) k^{\alpha-2} x^{\beta}+\widehat{\varphi} \alpha \beta k^{\alpha-1} x^{\beta-1}+\widehat{\psi}=0
\end{aligned}
$$

It follows from (53) and (54) that

$$
\mu_{h}-\mu_{f}=\psi-\widehat{\psi}-\lambda_{g} \tau r
$$


It follows from (55) and (56) that

$$
\widehat{\mu}_{h}-\widehat{\mu}_{f}=-\psi+\widehat{\psi}+\lambda_{g} \tau r
$$

From (57), we get

$$
\frac{\mu_{h}-\mu_{f}}{2 \gamma}=k_{h}\left(\lambda_{c}-\lambda_{g}\right)
$$

From (58), we get

$$
\frac{\widehat{\mu}_{h}-\widehat{\mu}_{f}}{2 \gamma}=k_{f} \lambda_{g}
$$

Hence, using (64) and (65)

$$
\left(\lambda_{g}-\lambda_{c}\right) k_{h}=\lambda_{g} k_{f}
$$

Insert (66) and (67) into (60). Then

$$
\begin{aligned}
\kappa= & \lambda_{c}\left[(1-\tau) k_{h}-\delta k\right]+\lambda_{g}[\tau k-(1-\delta) k] \\
& -k_{h}\left(\lambda_{c}-\lambda_{g}\right)(1-\tau)+k_{f} \lambda_{g}(1-\tau) \\
= & \left(\lambda_{g}-\lambda_{c}\right) \delta k
\end{aligned}
$$

Insert them in (61) as well. This gives

$$
\begin{aligned}
\widehat{\kappa} & =\lambda_{c}(1-\tau) k_{f}+k_{h}\left(\lambda_{c}-\lambda_{g}\right)(1-\tau)-k_{f} \lambda_{g}(1-\tau) \\
& =(1-\tau)\left(\lambda_{c}-\lambda_{g}\right) k
\end{aligned}
$$

Use $\kappa$ from (69) and $\varphi$ from (59) in (51) and (62) to get

$$
\begin{aligned}
& \omega=\lambda_{g} t+\delta\left(\lambda_{g}-\lambda_{c}\right)(\alpha+\beta-1) t \\
& \psi=\left(\lambda_{g}-\lambda_{c}\right) \delta r(1-\alpha-\beta)
\end{aligned}
$$

From (55), (58) with $\gamma \rightarrow 0$, (56) and (72) we have

$$
\hat{\psi}=\widehat{\mu}_{h}=\widehat{\mu}_{f}=\psi-\lambda_{g} \tau r=\left(\lambda_{g}-\lambda_{c}\right) \delta r(1-\alpha-\beta)-\lambda_{g} \tau r
$$

It follows from (73) and (70) in (63) that

$$
\begin{aligned}
0= & (1-\tau)\left(\lambda_{c}-\lambda_{g}\right) k \alpha(\alpha-1) k^{\alpha-2} x^{\beta}+\widehat{\varphi} \alpha \beta k^{\alpha-1} x^{\beta-1} \\
& +\left(\lambda_{g}-\lambda_{c}\right) \delta r(1-\alpha-\beta)-\lambda_{g} \tau r \\
= & (1-\tau)\left(\lambda_{c}-\lambda_{g}\right)(\alpha-1) r+\widehat{\varphi} \beta r / x+\left(\lambda_{g}-\lambda_{c}\right) \delta r(1-\alpha-\beta)-\lambda_{g} \tau r
\end{aligned}
$$

Hence,

$$
\widehat{\varphi} \beta / x=(1-\tau)\left(\lambda_{c}-\lambda_{g}\right)(1-\alpha)-\left(\lambda_{g}-\lambda_{c}\right) \delta(1-\alpha-\beta)+\lambda_{g} \tau
$$


Insert this and $\widehat{\kappa}$ in (52). Then

$$
\begin{aligned}
v= & (1-\tau)\left(\lambda_{c}-\lambda_{g}\right) k \alpha \beta k^{\alpha-1} x^{\beta-1} \\
& +\left[(1-\tau)\left(\lambda_{c}-\lambda_{g}\right)(1-\alpha)\right. \\
& \left.-\left(\lambda_{g}-\lambda_{c}\right) \delta(1-\alpha-\beta)+\lambda_{g} \tau\right] \frac{x}{\beta} \beta(\beta-1) k^{\alpha} x^{\beta-2} \\
= & (1-\tau)\left(\lambda_{c}-\lambda_{g}\right) \alpha t \\
& +\left[(1-\tau)\left(\lambda_{c}-\lambda_{g}\right)(1-\alpha)-\left(\lambda_{g}-\lambda_{c}\right) \delta(1-\alpha-\beta)+\lambda_{g} \tau\right] \frac{\beta-1}{\beta} t
\end{aligned}
$$

Hence,

$$
\begin{aligned}
\beta v= & (1-\tau)\left(\lambda_{g}-\lambda_{c}\right) t(1-\alpha-\beta)+\left(\lambda_{g}-\lambda_{c}\right) \delta(1-\alpha-\beta) t(1-\beta) \\
& -\lambda_{g} \tau t(1-\beta)
\end{aligned}
$$

So, using (71)

$$
\begin{aligned}
\frac{\beta v+(1-\beta) \omega}{\omega} & =(1-\tau) \frac{\left(\lambda_{g}-\lambda_{c}\right)(1-\alpha-\beta)+\lambda_{g}(1-\beta)}{\lambda_{g}-\delta\left(\lambda_{g}-\lambda_{c}\right)(1-\alpha-\beta)} \\
& =(1-\tau) \frac{\left(1-\frac{\lambda_{c}}{\lambda_{g}}\right)(1-\alpha-\beta)+(1-\beta)}{1-\delta\left(1-\frac{\lambda_{c}}{\lambda_{g}}\right)(1-\alpha-\beta)}
\end{aligned}
$$

Therefore, we can solve $\lambda_{c} / \lambda_{g}$ as a function of $\tau$ only. We also have

$$
\begin{aligned}
c & =(1-\tau) r k_{h}+(1-\tau) r k_{f}+\delta\left(k^{\alpha} x^{\beta}-r k-t x\right) \\
& =[(1-\tau) \alpha+\delta(1-\alpha-\beta)] k^{\alpha} x^{\beta} \\
g & =\tau r k+t x+(1-\delta)\left(k^{\alpha} x^{\beta}-r k-t x\right) \\
& =[1-(1-\tau) \alpha-\delta(1-\alpha-\beta)] k^{\alpha} x^{\beta}
\end{aligned}
$$

Hence,

$$
\frac{c}{g}=\frac{(1-\tau) \alpha+\delta(1-\alpha-\beta)}{1-\alpha(1-\tau)-\delta(1-\alpha-\beta)}
$$

Given (49) and (50) we get a second expression for $\lambda_{c} / \lambda_{g}$.

$$
\frac{\lambda_{c}}{\lambda_{g}}=\frac{1}{\varepsilon}\left(\frac{(1-\tau) \alpha+\delta(1-\alpha-\beta)}{1-\alpha(1-\tau)-\delta(1-\alpha-\beta)}\right)^{-\sigma}
$$

Hence, from (75) and (79), we can solve for $\tau$ for every given $\delta$. In order to solve for $x$, given $k$, consider (71), and use (49), (50), (76), and (77) to obtain

$$
\begin{aligned}
\omega x= & \left(\varepsilon \left([1-(1-\tau) \alpha-\delta(1-\alpha-\beta)]^{-\sigma}(1-\delta(1-\alpha-\beta)) \beta\left(k^{\alpha} x^{\beta}\right)^{1-\sigma}\right.\right. \\
& +[(1-\tau) \alpha+\delta(1-\alpha-\beta)]^{-\sigma} \delta(1-\alpha-\beta) \beta\left(k^{\alpha} x^{\beta}\right)^{1-\sigma}
\end{aligned}
$$




\section{References}

Bucovetsky, S., \& Wilson, J. (1991). Tax competition with two tax instruments. Regional Science and Urban Economics, 21, 333-351.

Ha, J., \& Sibert, A. (1997). Strategic capital taxation in large open economies with mobile capital. International Tax and Public Finance, 4(3), 243-262.

Hoel, M. (1997). Environmental policy with endogenous plant locations. Scandinavian Journal of Economics, 59, 17-32.

Kanbur, R., Keen, M., \& van Wijnbergen, S. (1995). Industrial competitiveness, environmental regulation and direct foreign investment. In I. Goldin \& L. A. Winters (Eds.), The economics of sustainable development (pp. 289-302). Cambridge: Cambridge University Press.

Kim, J., \& Wilson, J. (1997). Capital mobility and environmental standards: Racing to the bottom with multiple tax instruments. Japan and the World Economy, 9, 537-551.

Klein, P., Rios-Rull, V., \& Quadrini, V. (2005). Optimal time consistent taxation with international mobility of capital. Advances in Macroeconomics, 5 (1), article 2. Available at: http://www.bepress.com/ bejm/advances/vol5/iss1/art2.

Krumm, R., \& Wellisch, D. (1995). On the efficiency of environmental instruments in a spatial economy. Environmental and Resource Economics, 6, 87-98.

Lejour, A. M., \& Verbon, H. A. A. (1997). Tax competition and redistribution in a two-country endogenous-growth model. International Tax and Public Finance, 4, 485-497.

Levinson, A. (1997a). A note on environmental federalism: Interpreting some contradictory results. Journal of Environmental Economics and Management, 33, 359-366.

Levinson, A. (1997b). Environmental regulations and industry location: International and domestic evidence. In J. Bhagwati \& R. E. Hudec (Eds.), Economic analysis: Vol. 1. Fair trade and harmonization: prerequisites for free trade? (pp. 429-457). Cambridge: MIT Press.

List, J. A., \& Gerking, S. (2000). Regulatory federalism and environmental protection in the United States. Journal of Regional Science, 40(3), 453-471.

List, J. A., \& Mason, C. F. (2001). Optimal institutional arrangements for tranboundary pollutants in a second-best world: Evidence from a differential game with asymmetric players. Journal of Environmental Economics and Management, 42, 277-296.

Markusen, J., Morey, E., \& Olewiler, N. (1995). Competition in regional environmental policies when plant locations are endogenous. Journal of Public Economics, 56, 55-77.

Marsiliani, L., Renstrom, T., \& Withagen, C. (2004) Environmental policy and interjurisdictional competition in a second-best world (Mimeo). University of Durham.

Motta, M., \& Thisse, J. F. (1994). Does environmental dumping lead to delocation? European Economic Review, 38, 563-576.

Oates, W. E. (2002). A reconsideration of environmental federalism. In J. A. List \& A. De Zeeuw (Eds.), Recent advances in environmental economics (pp. 1-32). Cheltenham Glos: Edward Elgar.

Oates, W. E., \& Schwab, R. M. (1988). Economic competition among jurisdictions: Efficiency enhancing or distortion inducing? Journal of Public Economics, 35, 333-354.

Ogawa, H., \& Wildasin, D. (2009). Think locally, act locally: Spillovers, spillbacks, and efficient decentralized policymaking. American Economic Review, 99(4), 1206-1217.

Rauscher, M. (1995). Environmental regulation and the location of polluting industries. International Tax and Public Finance, 2, 229-244.

Rauscher, M. (2000). Interjurisdictional competition and the environment. In H. Folmer \& T. Tietenberg (Eds.), International yearbook of environmental and resource economics 2000/2001 (pp. 197-230). Cheltenham Glos: Edward Elgar.

Ulph, A. (1994). Environmental policy, plant location and government protection. In C. Carraro (Ed.), Trade, innovation, environment. Dordrecht: Kluwer Academic.

Venables, A. (1999). Economic policy and the manufacturing base: hysteresis in location. In R. Baldwin \& J. Francois (Eds.), Dynamic issues in applied commercial analysis. Cambridge: CEPR and Cambridge University Press.

Vig, N., \& Kraft, M. (1994). Environmental policy in the 1990s. Congressional Quarterly, Washington DC.

Wellisch, D. (1995). Locational choices of firms and decentralized environmental policy with various instruments. Journal of Urban Economics, 37, 290-310.

Wilson, J. D. (1997). Capital mobility and environmental standards: Is there a theoretical basis for a race to the bottom? In J. Bhagwati \& R. E. Hudec (Eds.), Economic analysis: Vol. 1. Fair trade and harmonization: Prerequisites for free trade? (pp. 393-427). Cambridge: MIT Press. 